\title{
PERÌPHERAL CIRCULATORY CHANGES ASSOCIATED WITH ARTERIOVENOUS ANEURYSMS
}

\author{
BY \\ G. M. WILSON \\ From the Department of Therapeutics, University of Sheffield and Sheffield Royal Infirmary, Sheffield
}

Received November 11, 1950

During recent years several investigations into the circulatory disturbances found with an ateriovenous fistula have been reported. Measurements of blood flow distal to arteriovenous fistulæ in man have been reported by Lewis and Drury (1923), Lewis (1940) and Cohen et al. (1948). In the two cases reported here, attention has been directed chiefly to the mechanism of the adjustment of the blood supply to the tissues distal to the fistulæ, as conflicting views have been expressed on this point (Holman, 1949). In the first case the fistula was in the deep femoral vessels and in the second, in the vessels of the thenar eminence of the hand. Both situations afforded favourable opportunities for the investigation of the distal circulation.

\section{Methods of Investigation of the Peripheral Circulation}

In the first case, the blood flow through the foot was determined in a venous occlusion plethysmograph filled with water maintained at $44^{\circ} \mathrm{C}$. The foot was kept in the instrument at this temperature for 45 minutes before observations were begun. This ensured full local vasodilatation and the tracings thus afforded a measurement of the maximal blood flow as defined by Kunkel and Stead (1938). The foot was kept at approximately heart level as no local venous engorgement was present and satisfactory inflow tracings were obtained at this height.

In the second case, the blood flow through the terminal two phalanges was measured in a calorimeter constructed on the principles described by Greenfield and Scarborough (1949) and Greenfield and Shepherd (1950). The tip of the finger being examined was supported on an adjustable platform, and it was thus possible to measure corresponding parts of each finger. The heat elimination was expressed as cal. $/ \mathrm{min} . / \mathrm{ml}$. of finger tissue. The observations were made with the water in the calorimeter between $28^{\circ}$ and $30^{\circ} \mathrm{C}$ but all the results have been expressed by the method of Cooper et al. (1949) as the rate of elimination of heat into water at $32^{\circ} \mathrm{C}$. The calorimetric method of measuring blood flow was chosen in preference to a finger venous occlusion plethysmograph as the venous pressure on the affected side was considerably elevated and the venous bed could not be effectively emptied by raising the hand. Under these circumstances it would not have been possible to obtain reliable arterial inflow tracings, especially as observations were required at full vasodilatation which in itself leads to rapid filling of the venous bed.

The systolic arterial pressure in the finger was obtained by the method described by Gaertner (1899). A small cuff was fitted over the proximal phalanx and, after exsanguinating the finger with a tight rubber bandage, was inflated above brachial systolic pressure. The bandage was removed and the pressure in the cuff was slowly reduced till a sudden flush of inflowing blood was observed in the finger tip. The pressure at this point was read as the digital arterial systolic pressure. A modification of this method was used for the determination of the blood pressure in the legs. The lower limbs were soaked in water at $43^{\circ} \mathrm{C}$ for 15 minutes to ensure dilatation of the cutaneous 
vessels. The legs were then elevated to blanch the skin and a cuff $20 \mathrm{~cm}$. in breadth was applied and inflated to above systolic pressure. The limbs were replaced in the water and the pressure was slowly reduced until the flush of reactive hyperæmia was observed in the feet. No reliable readings of diastolic pressure could be made using the cuff as described by Mendlowitz (1938) since the point at which throbbing disappeared could not be ascertained on the side with the fistula.

\section{Case Reports and Circulatory Measurements}

Case 1. A male, aged 38 years, was wounded in the right lower limb in March, 1944. Since then he has been aware of a swelling and throbbing in the right groin which have gradually increased. There has been no swelling of the distal part of the limb and apart from an increased liability to chilblains in the right foot there has been no disability.

On examination a pulsatile swelling with a marked thrill was present immediately below the right inguinal ligament in the line of the femoral artery. The thrill was readily abolished by local compression of the artery. The dorsalis pedis and posterior tibial pulses were present on both sides, but were abolished on the right side when the fistula was closed. No dilated veins were seen. The skin of the feet appeared healthy and there was no hypertrophy of the affected limb. After exposure of the feet in the laboratory at $19^{\circ} \mathrm{C}$ there was no difference in temperature between the two sides. There was clinical and radiological evidence of left ventricular enlargement. No abnormalities were detected in the other systems.

A surgical exploration was carried out by Mr. Clifford Jones and an arteriovenous fistula between the profunda femoris artery and vein close to the main artery was excised. The arteries immediately proximal and distal to the fistula were conspicuously enlarged.

Circulatory changes on closure of the fistula. The fistula was readily closed by pressure over the artery in the groin. The resulting changes in pulse rate, blood pressure in arm and legs and maximal blood flow in the feet are shown in Table I. They represent the averages of several observations which were uniformly consistent.

TABLE I

Circulatory Changes Associated with Closure of the Arteriovenous fistula in Case 1

\begin{tabular}{|c|c|c|c|c|}
\hline & \multicolumn{2}{|c|}{ Fistula open } & \multicolumn{2}{|c|}{ Fistula closed } \\
\hline Pulse rate per minute & \multicolumn{2}{|c|}{76} & \multicolumn{2}{|c|}{57} \\
\hline Blood pressure in left arm in $\mathrm{mm} . \mathrm{Hg}$. & \multicolumn{2}{|c|}{$135 / 80$} & \multicolumn{2}{|c|}{$150 / 98$} \\
\hline & Right & Left & Right & Left \\
\hline Systolic blood pressure in legs in $\mathrm{mm} . \mathbf{H g}$. & 75 & 115 & 55 & 125 \\
\hline Maximal blood flow in feet in $\mathrm{ml} . / \mathrm{min} . / 100 \mathrm{ml}$. & $14 \cdot 8$ & $13 \cdot 2$ & $7 \cdot 2$ & $17 \cdot 2$ \\
\hline
\end{tabular}

Pulse rate and brachial blood pressure. The fall in pulse rate and elevation of the general arterial pressure were similar to those described in previous accounts of fistulæ between these vessels (Holman, 1923; Laplace, 1935). Certain additional features were also observed electrocardiographically in association with these changes. Immediately after closure of the shunt and coincidental with the bradycardia a lengthening of the P-R interval was consistently seen. With the fistula open the interval was $0.16 \mathrm{sec}$. and this increased to $0.30 \mathrm{sec}$. when it was closed (Fig. 1). The character of the $P$ waves also altered and they became flatter in all leads and inverted in lead III. There were no changes in the ventricular complexes in either the standard or unipolar leads. In this subject similar changes were produced by digital compression of the right carotid sinus while the fistula was open. In experiments where the closure of the fistula was maintained over a period of a minute a continuous electrocardiogram showed that the changes were most pronounced in 


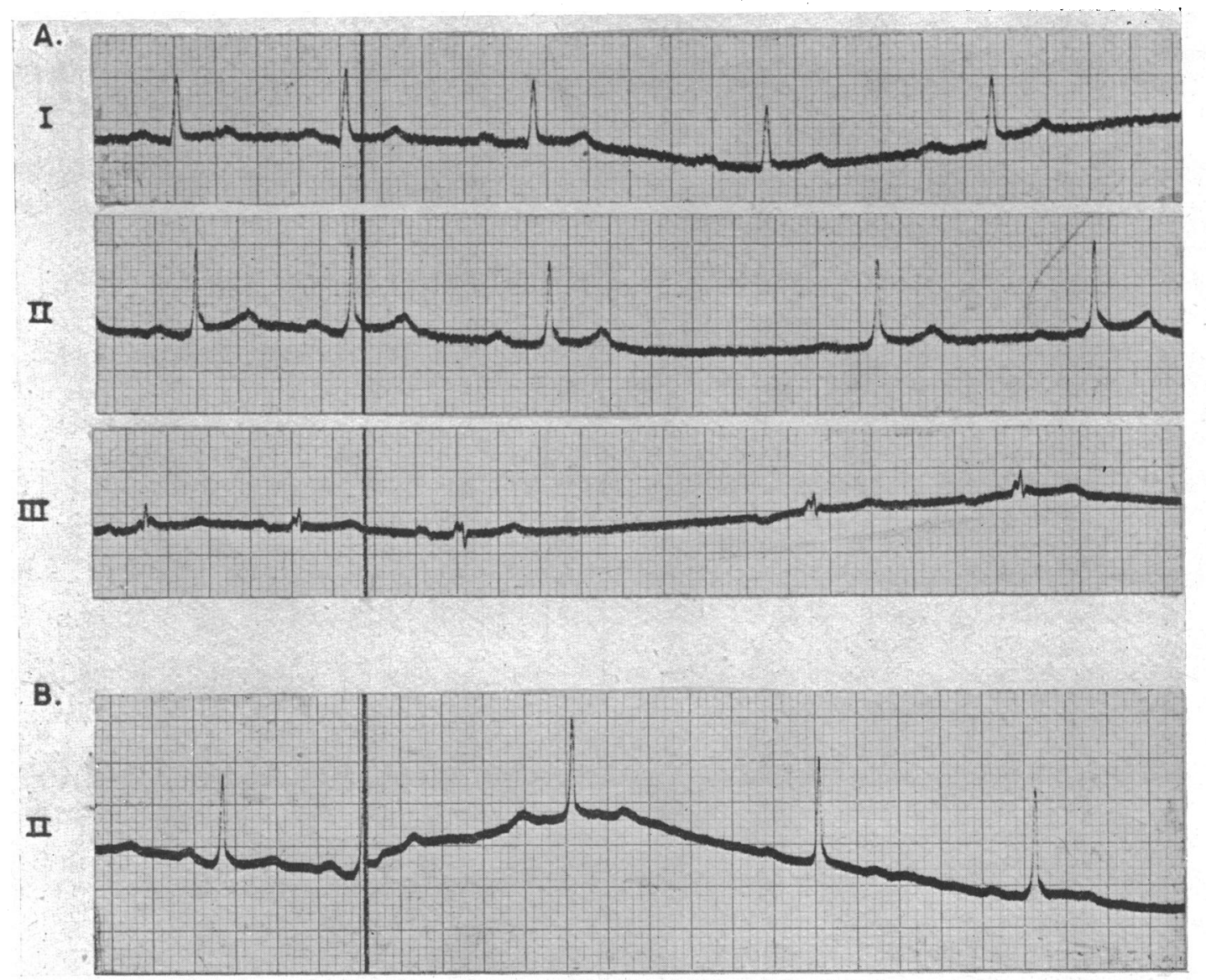

FIG. 1.-Electrocardiograms showing the effect of closing the fistula and of right carotid sinus pressure in Case 1. (A) Leads I, II, and III. Closure of the fistula at the point marked by the vertical line produced lengthening of

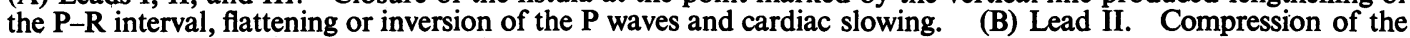
right carotid sinus produced similar changes.

the first few seconds. Thereafter the heart rate increased slightly, the P-R interval decreased and the $\mathbf{P}$ waves became more normal even though complete closure was apparently maintained. These results are consistent with the view that the changes were mediated through the vagus as a depressor reflex in response to the raised arterial pressure.

Peripheral circulatory changes. The alterations in the blood pressure and blood flow in the lower limbs were of considerable interest. With the fistula open the arterial pressure on the affected side was considerably less than on the normal side. Nevertheless, in spite of this reduced pressure, the maximal blood flow in the right foot was slightly greater than on the opposite side. These results indicated that an enlargement of the arteries had occurred in the foot on the side of the fistula to maintain the distal blood flow at this high level. Closure of the fistula produced different effects on the two sides. The increase in blood flow on the normal side was probably due to the rise in general arterial pressure, as under the experimental condition of full dilatation due to local heat it could not be attributed to a further release of vasoconstrictor tone. The femoral artery on the affected side was inevitably occluded when the fistula was closed and consequently. there was a decrease in both distal blood pressure and blood flow.

The validity of the plethysmographic method in making these measurements must be considered, especially on the side where the arterial pressure was greatly reduced. The pressure as measured 
with a cuff $20 \mathrm{~cm}$. in width was $75 \mathrm{~mm}$. of mercury. It was possible that the venous occlusion cuff of $4 \mathrm{~cm}$. in width might reduce the arterial inflow to the foot but comparison of inflow tracings with venous occlusion pressures of 70 and $50 \mathrm{~mm}$. showed no significant differences and on this evidence it was thought that the narrow venous occlusion cuff did not interfere materially with the arterial inflow. Obviously any error would be in the direction of an underestimation of the blood flow on the affected side and this would not alter the conclusion that the arteries distal to the fistula were considerably enlarged.

Case 2. A female, aged 34 years, had first noticed in February, 1947, a swelling at the base of the left thumb which slowly increased in size and began to pulsate. The veins above the wrist became grossly distended. The onset was gradual and she was unaware of any injury to the region. A diagnosis of an arteriovenous fistula was made and a surgical exploration was carried out in July, 1947. The fistula was not found and the radial artery was ligated at the wrist. In 1948 arteriography was twice attempted without success. After the second occasion the thumb, index and middle fingers became blue and cold owing to the development of arterial thrombosis. Subsequently, their condition slowly improved but they have always become excessively cold on exposure.

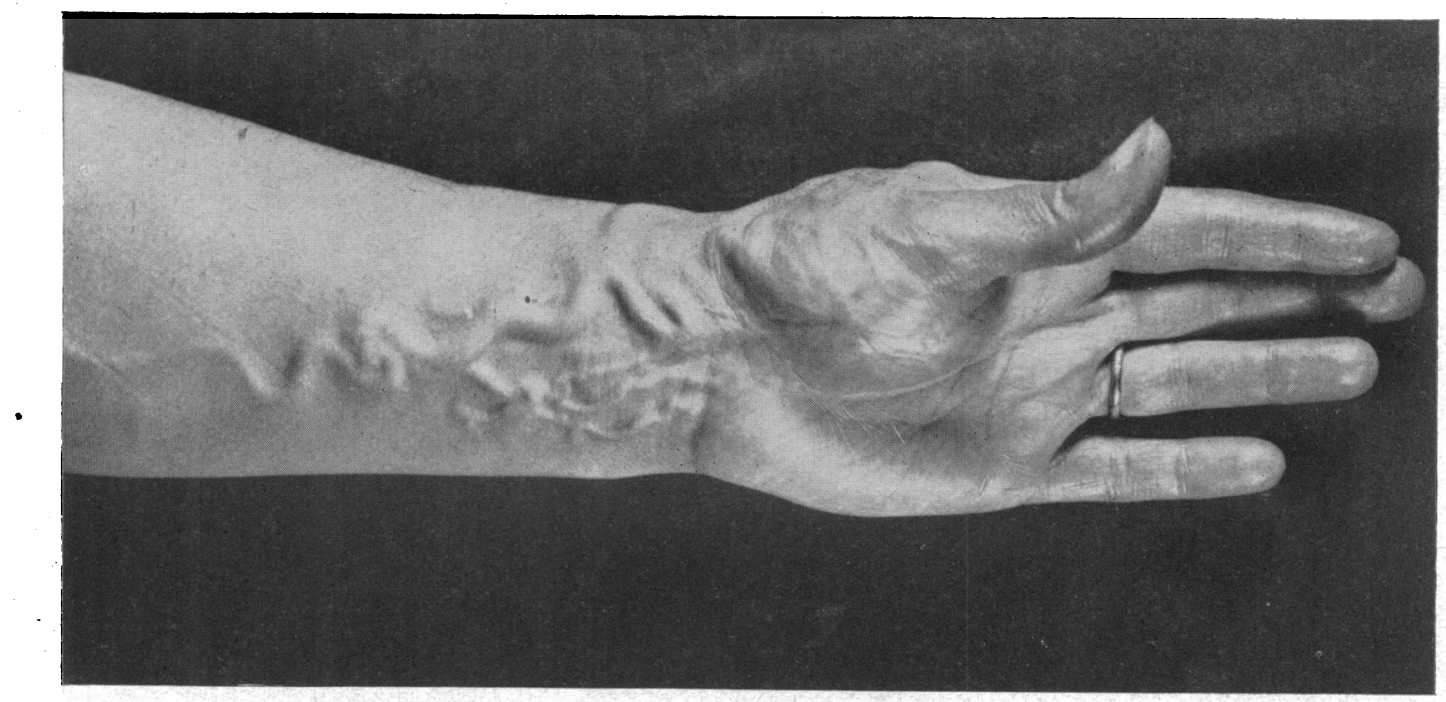

FIG. 2.-The left hand showing the swelling of the arteriovenous aneurysm in the thenar region and the dilated veins in the forearm.

On examination there was a firm smooth swelling in the thenar region of the left hand from which dilated veins ran proximally up the forearm (Fig. 2). These veins showed a distinct slight pulsation. After exposure for half an hour to ward temperature $\left(19^{\circ} \mathrm{C}\right)$ the thumb, index and middle fingers were cyanosed and colder than the other fingers of the left and right hands which were of equal temperature. A left radial pulse was distinctly felt in spite of the previous ligation, and a strong ulnar pulse was also present. A loud, prolonged systolic murmur was audible over these arteries and over the thenar swelling. Strong brachial arterial pulsations were palpable and a thrill and murmur were present over the whole length of the vessel. Apart from the local changes in the hand the limbs were of equal size. A radiograph of the hands showed no difference in structure between the bones. There was no clinical or radiological evidence of cardiac enlargement.

The clinical diagnosis was an arteriovenous aneurysm in the left thenar region with thromboses in the arteries supplying the thumb, index and middle fingers. As the nature and extent of the fistula were uncertain, comparative observations were made in the first place to determine whether the fistula could be adequately closed by local pressure. 
Pulse rate and brachial blood pressure. With the circulation to the left hand excluded by a cuff the heart rate consistently slowed. Numerous counts made by several different observers showed that the slowing was consistently in the range of 3 to 6 beats a minute. The average pulse rate was 72 and this fell to 68 when the cuff was inflated. Digital closure of the fistula gave a similar result. The average right brachial arterial pressure with the circulation free was 110/68 and with the left-arm cuff inflated the pressure was 110/74. The alteration in pressure was most convincingly demonstrated by maintaining the right arm sphygmomanometer at $70 \mathrm{~mm}$. At this level sounds were loudly heard with the flow through the arteriovenous aneurysm unchecked, but on stopping the flow either by inflating the left-arm cuff or by digital pressure the sounds promptly disappeared. The electrocardiograms taken in association with these changes were normal and only cardiac slowing was seen on closing the fistula.

Venous blood oxygen. Samples of blood were taken from a dilated vein at a point $12 \mathrm{~cm}$. above the fistula without proximal venous congestion. The first specimen was withdrawn with the fistula open. The fistula was then closed by digital pressure, the hand was elevated to empty the venous bed and then lowered to below heart level, pressure still being maintained over the fistula. After a further two minutes rest, a second specimen of blood was withdrawn. The blood was analysed in the manometric Van Slyke apparatus with the results given below.

\begin{tabular}{l|c|c}
\hline & $\begin{array}{c}\text { Vols. oxygen/100 ml. } \\
\text { blood }\end{array}$ & $\begin{array}{c}\text { Percentage } \\
\text { saturation }\end{array}$ \\
\hline Specimen 1. Fistula open. & $\begin{array}{c}15 \cdot 8 \\
11.8\end{array}$ & 96 \\
Specimen 2. Fistula closed. & 16.4. & 72 \\
Mixed 1 and 2. Saturated. & 100 \\
\hline
\end{tabular}

Venous Pressure. Measurement was made in a dilated vein at a point $8 \mathrm{~cm}$. proximal to the fistula by the direct method using a citrate manometer. The limb was maintained at approximately. heart level with the patient lying flat and the pressures are expressed in relation to the sternal angle. With the fistula open the average reading was $+19 \mathrm{~cm}$. Unusually large pulsations were observed in the manometer. On digital closure of the fistula in repeated experiments, the pressure fell rapidly to approximately $+8 \mathrm{~cm}$.

It was concluded that all these observations indicated that digital pressure effectively shut the arteriovenous aneurysm and that an investigation of the distal circulation might be carried out using this method of closure.

Capillary Pulsation. After soaking both hands in water at $43^{\circ} \mathrm{C}$. for 15 minutes the finger tips and nail beds were inspected for capillary pulsation. This was readily seen in all the right-hand fingers and was not appreciably altered by opening and closing the fistula. In the left hand it was observed in the ring and little fingers to a slight degree with the fistula open, and conspicuously with the fistula closed. No pulsation was seen in the index or middle fingers with the fistula either open or closed, results consistent with the presence of thrombosis in their digital arteries.

Digital arterial pressure and blood flow. The results obtained in all the fingers of both hands are shown in Table II. The investigations were performed at least in duplicate and were consistent on the separate occasions. The measurements were all made at full reflex vasodilatation obtained by immersing the feet in stirred water at $43^{\circ} \mathrm{C}$. The observations were not begun until the patient was sweating freely and the heat elimination had reached a steady high level.

In the right fingers the systolic pressure was not significantly affected by closing the fistula but the blood flow as reflected by the heat elimination always rose slightly. The average increase was 12 per cent and this was attributed to the rise in general diastolic pressure. Pressure of an equal degree on the left hand other than over the fistula did not alter the blood pressure or flow.

In the left hand the digital pressures with the fistula open were conspicuously reduced in comparison with the right hand; on closure of the fistula they all rose to a height comparable with that in 
TABLE II

Arterial Systolic Pressure and Heát Elimination of the Fingers Measured at Full Reflex VASODILATATION

\begin{tabular}{|c|c|c|c|c|c|}
\hline \multirow{2}{*}{\multicolumn{2}{|c|}{ Finger }} & \multicolumn{2}{|c|}{ Fistula open } & \multicolumn{2}{|c|}{ Fistula closed } \\
\hline & & $\begin{array}{l}\text { Blood Pressure } \\
\text { (mm. mercury) }\end{array}$ & $\begin{array}{l}\text { Heat elimination } \\
\text { (cal./min./ml.) }\end{array}$ & $\begin{array}{l}\text { Blood Pressure } \\
\text { (mm. mercury) }\end{array}$ & $\begin{array}{l}\text { Heat elimination } \\
\text { (cal./min./ml.) }\end{array}$ \\
\hline Index & $\begin{array}{l}\text { right } \\
\text { left }\end{array}$ & $\begin{array}{l}75 \\
36\end{array}$ & $\begin{array}{l}2 \cdot 2 \\
0.3\end{array}$ & $\begin{array}{l}78 \\
80\end{array}$ & $\begin{array}{l}2.5 \\
0.5\end{array}$ \\
\hline Middle & $\begin{array}{l}\text { right } \\
\text { left }\end{array}$ & $\begin{array}{l}82 \\
40\end{array}$ & $\begin{array}{l}2 \cdot 3 \\
1 \cdot 5\end{array}$ & $\begin{array}{l}82 \\
80\end{array}$ & $\begin{array}{l}2 \cdot 4 \\
2 \cdot 0\end{array}$ \\
\hline Ring & $\begin{array}{l}\text { right } \\
\text { left }\end{array}$ & $\begin{array}{l}79 \\
40\end{array}$ & $\begin{array}{l}2 \cdot 5 \\
2 \cdot 6\end{array}$ & $\begin{array}{l}83 \\
82\end{array}$ & $\begin{array}{l}2 \cdot 8 \\
4 \cdot 3\end{array}$ \\
\hline Little & $\begin{array}{l}\text { right } \\
\text { left. }\end{array}$ & $\begin{array}{l}81 \\
40\end{array}$ & $\begin{array}{l}2.2 \\
1.9\end{array}$ & $\begin{array}{l}87 \\
83\end{array}$ & $\begin{array}{l}2.6 \\
3.4\end{array}$ \\
\hline
\end{tabular}

the normal hand. These differences were also readily demonstrated by deflating the cuff pressure on the left third, fourth, or fifth fingers to any level between $45 \mathrm{~mm}$. and $80 \mathrm{~mm}$. with the fistula open. The fingers remained blanched but on compression of the fistula immediate flushing occurred. In the left index finger the pressures both with the fistula open and closed were consistently slightly lower than in the other fingers of the left hand. It will be seen that in all the fingers the systolic arterial pressure approximately doubled on closing the fistula.

The changes in blood flow in the left hand were equally striking. In the index finger the heat elimination was exceptionally low in compatison with the corresponding normal right finger. The heat elimination in the left middle finger was also significantly reduced, though not to such a conspicuous degree. The low results were attributed to the previaus arterial thrombosis. In both these fingers there was a great relative increase in blood flow on closing the fistula. In the left ring and little fingers the heat eliminations with the fistula open were similar to those of the corresponding fingers of the normal hand. On closure of the fistula, however, there was a great increase in the heat elimination to a level 'considerably above that obtained in the contralateral fingers. The actual readings obtained in one representative experiment involving the ring fingers is shown in Fig. 3. The average increase in heat elimination of all the fingers resulting from closure of the fistula was 61 per cent. Digital pressure on the aneurysm caused some discomfort but it was shown that an equal degree of pressure on the right thenar eminence did not alter the blood flow through the left fingers. The effect of pressure on an artery proximal to the fistula was determined by digital occlusion of the left radial artery while the heat elimination from the left ring finger was being measured: the freely pulsating ulnar artery, was left unobstructed. This experiment shows that the blood flow through the ring finger was decreased (Fig. 4).

The results of the circulatory measurements in this case, as in the first case, demonstrated clearly that there was a persistent enlargement of the arteries unaffected by thromboses distal to the fistula. In spite of the disparity in digital blood pressures with the fistula open the blood flows were approximately equal on the two sides. With the fistula closed the pressures were similar but the blood flows were considerably greater than normal on the affected side.

\section{Discussion}

The arteriovenous fistula in the first case was traumatic in origin but the exact nature of the lesion in the second was difficult to determine. An injury or bruise not causing penetration of the skin may be the apparent starting point of an arteriovenous shunt (Reid, 1925b) but the patient was 


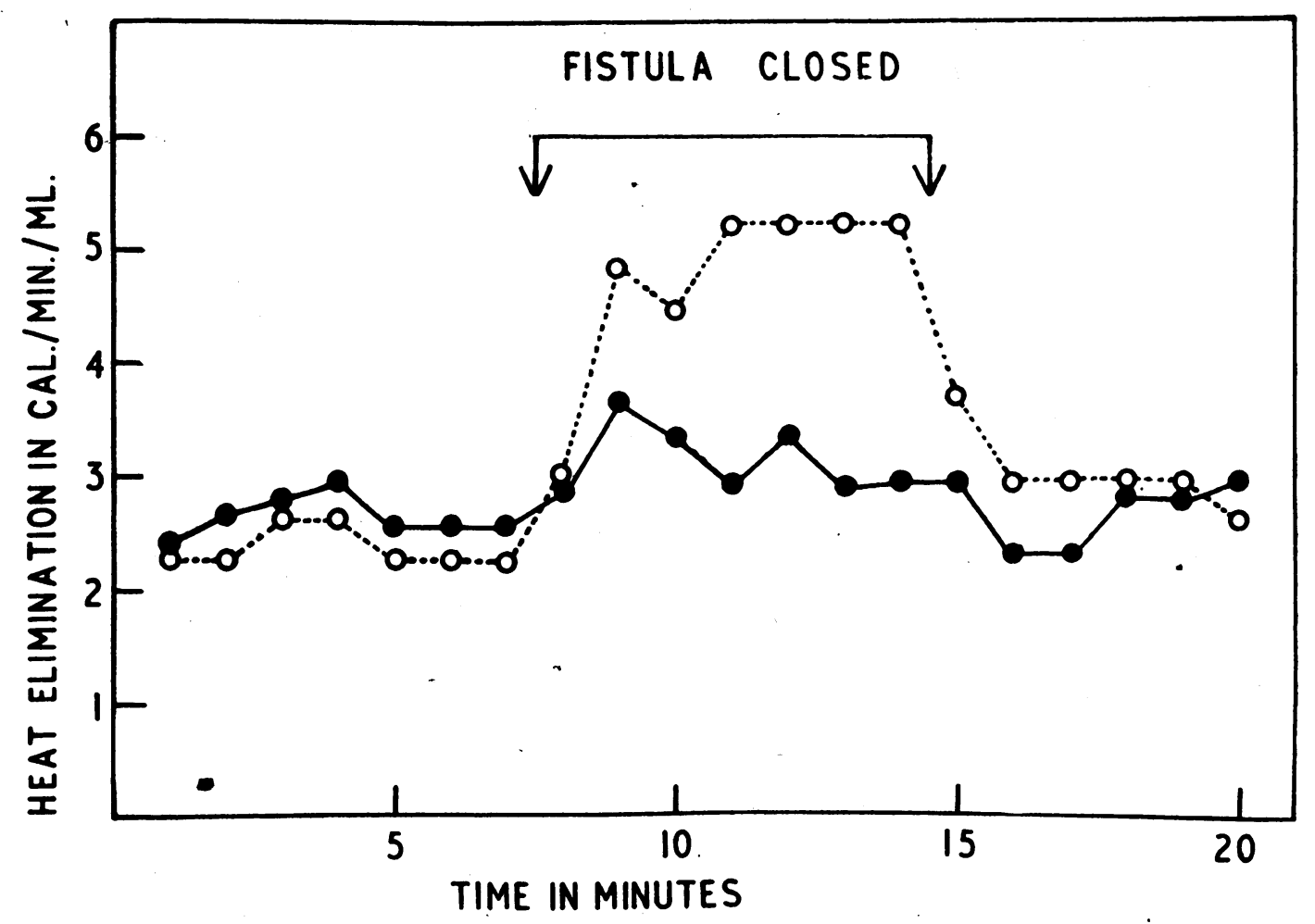

FIG. 3.-The effect of digital closure of the arteriovenous fistula on the heat elimination of the index fingers; right -0 , left o- 0 . The blood flows at full reflex vasodilatation were similar on the two sides with the fistula open. Closure of the fistula led to a slight increase on the normal side and a greater increase on the side of the fistula.

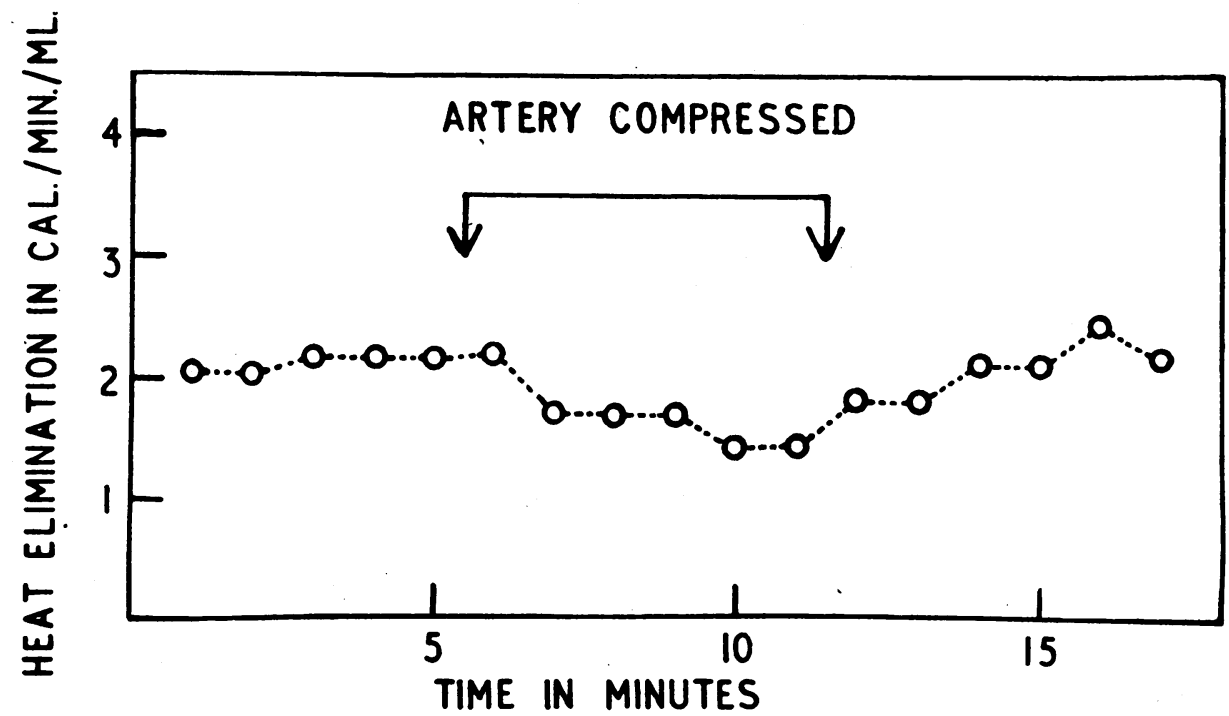

FIG. 4.-Compression of the radial artery immediately proximal to the fistula led to a decrease in the heat elimination of the left ring finger. 
unable to recollect any trauma. The condition was thus apparently of congenital origin, in spite of her age at its onset. Several cases of congenital arteriovenous aneurysms in the hand have been reported (Callander, 1920; Reid, 1925a; Pemberton and Saint, 1928; Horton, 1932) and occasionally the abnormality has not been noted until adult life (D. D. Lewis, 1930; Horton and Ghormley, 1933). The absence of cardiac enlargement and of hypertrophy of the limb is consistent with the view that the fistula is small and not of longer duration than the history suggests.

The blood flow measurements in the first case were similar to those previously recorded by Lewis and Drury (1923), Lewis (1940) and Cohen et al. (1948). In their cases of over two years duration, and thus comparable to the two reported here, the blood flow on the affected side was either similar to, or greater than, that on the normal side. Closure of the fistulæ always led to a decrease in the distal blood flow but the fistulæ involved the main limb vessels and the change in the distal arterial pressure was not ascertained. In the second case reported here with the fistula in the thenar eminence the collateral arteries were not occluded when the fistula was closed. The distal pressure increased to normal and the blood flow rose to considerably above normal. These results resemble those described by Robertson et al. (1950) who in experiments on dogs found that occlusion of an arteriovenous shunt increased the blood flow to the distal part of the extremity between 40 and 210 per cent and that this was associated with a considerable rise in the distal arterial pressure.

The enlargement of the arteries distal to an arteriovenous fistula is of considerable interest. The dilatation in the neighbourhood of the aneurysm is probably the direct result of distension by an increased volume of blood flowing to the shunt as suggested by Holman (1949). This mechanism may also account for the enlargement immediately distal to the aneurysm where there is a retrograde flow of blood. The enlargement of the arteries in the foot and the fingers in the two cases described cannot, however, be explained in this manner. They are not concerned in carrying blood to the fistulæ and the pressure within them cannot have caused any undue distension. In fact they have enlarged in spite of the greatly reduced pressure distal to the fistula and it appears that the necessary adjustment of blood flow is not effected by purely mechanical means. However, the suggestion of Lewis (1940) that a chemical substance originating in ischæmic tissue is responsible for the distal dilatation may apply in these circumstances. The greatly reduced arterial pressure will adversely affect filtration of fluid in the capillaries and, even though the volume of blood flow is normal, tissue nutrition may be inadequate. This may account for the recurrent cutaneous lesions in the first case in spite of the large blood flow. It may also explain the increase in distal blood flow to above normal levels in very long-standing cases of arteriovenous aneurysm.

With regard to treatment, the dangers associated with interference with the proximal arterial -supply have long been recognized (Reid, 1925c) and have been amply demonstrated in the second case in which compression of the radial artery immediately proximal to the fistula reduced the blood flow to the medial fingers even though a large pulsating ulnar artery was present. The fistula, constituting a site of low resistance, had the first claim on the blood flow and an attempt to reduce its supply merely led to deviation of blood from the tissues to maintain the flow through the shunt. Furthermore, proximal interference will reduce even lower the blood pressure distal to the fistula and it is not surprising that thrombosis in this region is a recognized consequence of this procedure (D. D. Lewis, 1930; Wilbur, 1930). It is clear from the physiological studies that the only satisfactory solution is complete extirpation of the fistula, as in the first case. This operation is often fraught with great technical difficulties, especially in the congenital cases, and has not again been attempted in the second case.

\section{SUMMARY}

Two cases of arterioventous fistula have been described with particular reference to the peripheral circulation and the condition of the arteries distal to the fistula.

In the first case the fistula was between the deep femoral vessels and was of six years' duration. 
Closure of the fistula produced considerable cardiac slowing and rise in blood pressure. These changes were associated with a lengthening of the $P-R$ interval and abnormalities in the $P$ waves attributed to excessive vagal activity. The blood pressure in the limb distal to the fistula was considerably reduced but the blood flow in the foot was slightly greater than on the normal side.

In the second case the fistula was situated in the thenar region of the hand and was of three and a half years' duration. A relatively slight decrease in heart rate and increase in diastolic pressure on checking the flow through the fistula showed that it was small. In the fingers on the affected side with patent digital arteries, the blood pressure with the fistula open was greatly reduced but the blood flow was similar to that on the normal side. Closure of the fistula increased the blood pressure to that on the normal side and the blood flow to above the normal.

These changes in the circulation indicated a persistent enlargement of arteries supplying tissues distal to the aneurysms. As the pressure in these arteries was unduly low and they were not concerned with the supply of blood to the fistulæ the enlargement could not be attributed to mechanical causes. The features were consistent with the hypothesis of Lewis that the enlargement was due to locally formed metabolites.

Occlusion of an artery immediately proximal to a fistula resulted in a deviation of blood from the distal tissues to the fistula and illustrated the dangers associated with interference with the proximal arteries. The only satisfactory treatment is complete extirpation of the fistula.

It is a pleasure to express my thanks to Mr. Clifford Jones and Professor E. J. Wayne for permission to publish the case reports and for help and advice; to Dr. A. G. MacGregor, Dr. P. Stanfield, Mr. A. G. Barritt and Mr. P. B. Moxon for assistance in making some of the observations; to $\mathrm{Mr}$. E. Salvin for the oxygen determinations; to Mr. R. Brook for the clinical photograph; and to the patients for their co-operation throughout the investigations.

The investigation was aided by a grant from the Medical Research Fund of the University of Sheffield.

\section{REFERENCES}

Callander, C. L. (1920). Johns Hopkins Hosp. Rep., 19, 259.

Cohen, S. M., Edholm, O. G., Howarth, S., McMichael, J., and Sharpey-Schafer, E. P. (1948). Clin. Sci. 7, 35. Cooper, K. E., Cross, K. W., Greenfield, A. D. M., Hamilton, T. McK., and Scarborough, H. (1949). Ibid., 8, 217. Gaertner, 'G. (1899). Wien. klin. Wschr., 12, 696.

Greenfield, A. D. M., and Scarborough, H. (1949). Clin. Sci., 8, 211.

, and Shepherd, J. T. (1950). Ibid., 9, 323.

Holman, E. (1923). Arch. Surg., 7, 64.

(1949). Surgery, 26, 889.

Horton, B. T. (1932). J. Amer. med. Ass., 98, 373.

, and Ghormley, R. K. (1933). Proc. Mayo Clin., 8, 773.

Kunkel, P., and Stead, E. A. (1938). J. clin. Invest., 17, 715.

Laplace, L. B. (1935). Amer. J. med. Sci., 189, 497.

Lewis, D. D. (1930). Lancet, 2, 621.

Lewis, T. (1940). Clin. Sci., 4, 277.

and Drury, A. N. (1923). Heart, 10, 301.

Mendlowitz, M. (1938). Clin. Sci., 3, 387.

Pemberton, J. de J., and Saint, J. H. (1928). Surg. Gynec. Obstet., 46, 470.

Reid, M. R. (1925a). Arch. Surg., 10, 601.`

- (1925b). Ibid., 10, 997.

- (1925c). Ibid., 11, 237.

Robertson, R. L., Dennis, E. W., and Elkin, D. C. (1950). Surgery, 27, 1.

Wilbur, D. L. (1930). Amer. J. med. Sci., 180, 221. 